\title{
Retornando sua coleção de material audiovisual: os dilemas de uma antropóloga
}

Restituer sa propre collection de matériaux audiovisuels : les dilemmes d'une anthropologue

Returning one's own audio-visual collection: an anthropologist's dilemma

\section{Clarice Cohn}

\section{CpenEdition}

\section{Journals}

Edição electrónica

URL: https://journals.openedition.org/jsa/18556

DOI: $10.4000 /$ jsa. 18556

ISSN: 1957-7842

\section{Editora}

Société des américanistes

Edição impressa

Data de publição: 15 dezembro 2020

Paginação: 105-127

ISSN: 0037-9174

\section{Refêrencia eletrónica}

Clarice Cohn, «Retornando sua coleção de material audiovisual: os dilemas de uma antropóloga »,

Journal de la Société des américanistes [En ligne], 106-2 | 2020, mis en ligne le 30 décembre 2020,

consulté le 16 septembre 2022. URL : http://journals.openedition.org/jsa/18556 ; DOI : https://doi.org/ $10.4000 /$ jsa. 18556 


\title{
Retornando sua coleção de material audiovisual: os dilemas de uma antropóloga
}

\author{
Clarice $\mathrm{COHN} *$
}

O texto trata de uma experiência de retornar o material audiovisual até então em formato analógico que faz parte da coleção etnográfica da autora. A partir da demanda de jovens Xikrin (Mebengokré), povo indígena do Pará (Brasil) com o qual trabalha desde 1992, que gostariam de se ver quando crianças, o material foi digitalizado e apresentações nas aldeias foram organizadas. $\mathrm{O}$ texto reflete sobre essa experiência a partir das descobertas, mas também dos desconfortos que ela trouxe tanto para a antropóloga quanto para os Xikrin. Esse processo é analisado com base nas concepções e nas práticas de aprendizagem xikrin, que enfatizam a audição e o olhar, uma reflexão sobre regimes de conhecimento e a circulação registrada, e questões relativas à relacionalidade, tais como parentesco e aparentamento, crescimento, cuidado, mas também mortes e perdas. [Palavras-chave: Xikrin, Mebengokré, Kayapó, coleções etnográficas, conhecimentos indígenas, aprendizagem, parentesco.]

Restituer sa propre collection de matériaux audiovisuels : les dilemmes d'une anthropologue. L'article traite d'une expérience de restitution du matériel audiovisuel ethnographique de l'auteure, essentiellement composé de photos argentiques des Xikrin (Mebengokré), population autochtone du Pará (Brésil) avec laquelle elle travaille depuis 1992. En réponse à la demande de jeunes adultes qui désiraient se voir tels qu'ils étaient enfants, le matériel fut numérisé et présenté dans les villages. Le texte propose une réflexion sur cette expérience, à partir des découvertes mais également des malaises qu'elle suscita, autant pour les Xikrin que pour l'auteure. Ce processus est analysé à partir des conceptions et des pratiques amérindiennes liées à l'apprentissage - lesquelles mettent l'emphase sur l'écoute et le regard -, et s'accompagne d'une réflexion sur les régimes de savoir et les discours que la circulation des enregistrements suscite concernant l'évolution du tissu social et des relations interpersonnelles, le rapport aux défunts, ou encore le changement culturel. [Mots-clés : Xikrin, Mebengokré, Kayapó, collection ethnographique, savoir indigène, apprentissage, parenté.]

* Professora da Universidade Federal de São Carlos, Brasil, Bolsista Produtividade CNPq [clacohn@gmail.com]. 
Returning one's own audio-visual collection: an anthropologist's dilemma. This paper focuses on the author's endeavor to return audiovisual material (essentially analogue photographs) from her personal archives to the Xikrin (Mebengokré) of Pará, Brazil, with whom she has been working since 1992. To comply with young adults' request to see what they looked like as children and how life was then, the documents were scanned and copies exhibited in the villages. The text offers a reflection on this experience, insisting on the discoveries it allowed but also on the discomfort it sometimes triggered, for both the author and her Xikrin friends. Analysis is based on Amerindian concepts and practices regarding the learning process - based on listening and watching-, and leads to reflections on indigenous conceptions of knowledge. Attention is paid to the stories that the circulation of recordings of past events brought about, concerning the evolution of social structure, interpersonal relations, connection with the dead, and cultural change in general. [Key words: Xikrin, Mebengokré, Kayapó, anthropological collections, indigenous knowledge, learning, kinship.]

Os Xikrin recentemente se reviram em imagens e sons que datam de trinta ou vinte anos atrás por meio de fotos e gravações em áudio que foram por mim feitas e retornadas a eles em 2017. É sobre esse processo, visto tanto do ponto de vista da antropóloga - e suas redescobertas, seus incômodos e desafios quanto deles de que trata este artigo. ${ }^{1}$ Como se verá, essa não foi a única vez que meus registros retornaram a eles; muito pelo contrário, essa foi sempre uma rotina na nossa relação, que data desde 1992. Mas 2017 marcou o momento em que os registros realizados antes da era digital voltaram a ser vistos e a circular pelas aldeias. E é um contexto excepcional, que dá ainda outro valor a esta atividade, já que marcado por um momento de crise, tendo em vista a construção da Usina Hidrelétrica de Belo Monte, a iminência da abertura da mineração a céu aberto Belo Sun, e uma onda de invasões na Terra Indígena. ${ }^{2}$

Antes, uma palavra sobre a coleção propriamente dita. Iniciada em 1992, ela reuniu registros por cerca de década e meia com câmaras de rolos de filmes e gravadores de fitas, até que pude retornar com câmeras e gravadores digitais. Foi então marcada por um duplo e dialógico interesse - o meu, como antropóloga, que tinha como tema de pesquisa, à época, as crianças, e o deles, que,

1. Uma primeira versão deste texto foi discutido no Simpósio Digital repatriation of traditional indigenous knowledge: a threat or an asset for its transmission?, organizado por Philippe Erikson e Valentina Vapnarsky, em 2018, no $56^{\circ}$ Congresso Internacional de Americanistas, e agradeço a ambos, como a todos os participantes do Simpósio, por suas colaborações. Agradeço em especial à leitura cuidadosa de Philippe Erikson e Valentina Vapnarsky, que em muito aprimoraram o texto, e aos pareceristas anônimos da revista.

2. Ver, para este momento, Cohn (2014), Mantovanelli (2016), Tselouiko (2018), Xikrin (2014), Oliveira e Cohn (2014). 
tendo pouco acesso às tecnologias de registro, ${ }^{3}$ me pediam para registrar seu kukradjà, uma palavra de amplo campo semântico que abrange tanto os modos de fazer quanto os produtos do que chamam de Mebengokré, normalmente tratado por uma autodenominação, mas que argumento ser uma condição de ser e estar no mundo (Cohn 2005), e que, como veremos, é com frequência traduzida por cultura pelos Xikrin. ${ }^{4}$ Dialógica propriamente dita, primeiro, porque as crianças são o mote, o centro e o motor da vida xikrin - é para elas que se fazem as coisas, é sobre seus futuros que se preocupam, é sobre elas a maior parte das conversas cotidianas, é a elas que estão todos e todas sempre atentos; em segundo lugar, porque, como provavelmente todo antropólogo, o que aprendi com os Xikrin foi exatamente o que quiseram me ensinar, e na medida em que me percebiam pronta para aprendê-lo. Não tendo sido "feita" como uma Xikrin - como uma Mebengokré -, minhas habilidades estavam já de início prejudicadas; meus ouvidos não receberam, no momento adequado, na infância, o tratamento necessário para melhor aprender, meu corpo não foi formado do modo a viver com eles suas vidas. A sua paciência excepcional, marcada, claro, por ímpetos de impaciência, foi o que me permitiu aprender

3. Atualmente, minha câmara digital e meu celular, que permitem fotografar, filmar e fazer gravações, com a vantagem de poderem ser vistos e circulados imediatamente, ultrapassaram em muito isso que chamei de relação dialógica na produção de registros, já que eles os pegam logo em minha chegada para fazerem, eles mesmos, a documentação; assim, meus registros de campo vão ficando cada vez menos autorais e mais coletivos.

4. Ambos os termos, Mebengokré e kukradjà, se abrem a amplos campos semânticos e, argumento, estão ligados entre si. O primeiro é com frequência associado a contextos relacionais e, por vezes, identitários, sendo este último uso uma resposta à etnicização na relação com o Estado. Mas, mais amplamente, ser Mebengokré remete a uma condição no mundo, a um modo de ser, de se comportar e, principalmente, a certa ética, etiqueta e estética; Vidal (1992), aliás, foi a primeira autora a apontar como estética e ética estão imbricados no mundo xikrin. O segundo, que por vezes é traduzido pelos Xikrin por cultura, é extremamente complexo e abrange praticamente, se não totalmente, tudo o que há no mundo (Cohn 2005, 2006; Demarchi 2014). Ele pode ser desdobrado, também, referindose às prerrogativas de pessoas, coletivos, gêneros, idades, ou falar de uma coletividade que abrange todos, me nhõ kukradjà. Argumento que seu caráter mais proeminente é sua capacidade de diversificação contínua, e nesse processo de diversificação é que estaria seu potencial - ao contrário de uma tendência de leitura culturalista a que se poderia levar os muitos usos como cultura (ver Cohn 2006). O kukradjà compõe pessoas e coletivos, é parte delas, e também o que se transmite entre parentes e gerações; são coisas, mas são também conhecimentos e saberes; e são rituais e festas que fazem as pessoas e os coletivos belos, mei. Assim, fazer um e se fazer mebengokré é se fazer (e fazer) por meio do kukradjà, que, por sua vez, se define como tal por ser o modo, e dos, Mebengokré. Desenvolvo e busco dar conta dessa complexidade em diversos momentos de meu trabalho - em Cohn (2000, 2016), exploro a definição de kukradjà como conhecimentos, ou o que é cogniscível; em Cohn (2005), nesta relação com ser, fazer e se fazer Mebengokré, e em sua necessidade de diferenciação contínua; e em Cohn (2006), analiso um discurso do então chefe Bep-tok no qual ele remete a esses termos e suas modificações, e riscos. 
algo sobre o que é ser um(a) Xikrin, crescer como um(a) Xikrin, e conhecer o mundo tal como um(a) Xikrin.

Em minha falta das habilidades auditivas para tal - e os Xikrin enfatizam que aprender é ouvir, ver e refletir com o ouvido, para o que preparam olhos e ouvidos desde sempre -, e tendo tido contato com outros pesquisadores, ${ }^{5}$ eles me instigavam a usar sempre os instrumentos mnemônicos que já sabiam imprescindíveis para suprir essa minha (nossa, dos não-Mebengokré) incapacidade: não foram poucas as vezes em que o velho Bep-Mojpá me mandou anotar o que dizia (desde quando eu ainda não conseguia de fato entendê-lo ou grafar algo que me fosse compreensível ao retomar as notas), assim como o velho Kuprore me instava a usar sempre o gravador e, também, todos, a câmera.

\section{A coleção da antropóloga e os muitos retornos dos registros aos Xikrin do Bacajá}

Desde que comecei a pesquisar com os Xikrin do Bacajá, levei uma câmara fotográfica, rolos e rolos de filmes e um gravador - no início um de fita K7, depois o "minigravador" (gravador ngrire, como eles diziam e os encantava, sendo ngrire "pequeno"), com as pequenas fitas. Foi mais de década utilizando esta tecnologia, até que ela foi substituída pela digital. Durante todos esses anos, a cada retorno às aldeias, levava comigo ampliações das fotos tiradas na viagem anterior, que buscava - frequentemente sem muito sucesso, dado o interesse coletivo em todas as fotos - distribuir pelas casas e pelas famílias retratadas. ${ }^{6}$ Esse momento era um dos que marcavam a alegria do reencontro, em que todos me cercavam, comentavam as fotos, brincavam, riam, e as faziam circular. Já nesse tempo, esse também era um momento marcado pela tristeza, ou por seu risco - afinal, na época, tínhamos poucos meios de comunicação, e eu só ficava sabendo das perdas e das mortes quando da minha chegada, às vezes levando imagens de falecidos(as), sem sabê-lo de antemão, circulando-as.

5. Dentre estes pesquisadores, estão Lux Vidal, minha orientadora desde a graduação e durante o mestrado, que me introduziu no trabalho com os Xikrin, e William Fisher, com quem pude compartilhar períodos de campo e manter um diálogo contínuo.

6. Nessas quase três décadas houve uma grande mudança na configuração das aldeias e de sua distribuição na Terra Indígena Trincheira-Bacajá. Iniciando-se com uma, a década de 1980 viu a primeira divisão para duas (ver Fisher 1991), e atualmente são 18. Minhas pesquisas foram acompanhando essas mudanças, em que me vejo com amigos e parentes distribuídos ao longo de toda a extensão da Terra Indígena, e os desafios logísticos de visitar todos. Para a apresentação das fotos, todas as aldeias existentes à época foram visitadas. Durante a pesquisa de mestrado, em que o esforço etnográfico que teve por mote as crianças foi preponderante, fonte de grande parte das fotos, minha pesquisa se concentrava na aldeia Bacajá, por muito tempo a maior e mais duradoura da Terra Indígena, e primeira aldeia após o contato, começando a se ampliar ainda na década de 1990, o que comento em tese sobre minha pesquisa posterior (Cohn 2005). 
Mas a alegria superava as eventuais tristezas, e as risadas felizes em se verem nas fotos ampliadas em papel eram ouvidas por toda a aldeia. Porém, como é de imaginar, a própria circulação das fotos de mão em mão neste suporte tão perecível lhes dava uma vida muito curta. Geralmente, de fato, elas não duravam mais do que o dia da minha chegada na aldeia. E sua circulação começava pelas mãos das mulheres - minhas companheiras mais frequentes, e meio de fazer o ir e vir pelas casas, que são delas mais do que dos homens - passando umas às outras, com os homens vendo as fotos por sobre os ombros delas, logo chegando às crianças, que já as estavam reclamando há tempos. Nas mãos das crianças, já manchadas de urucum, jenipapo e terra, eram apropriadamente lambidas, mordidas, amassadas e acabavam no chão, em algum lugar próximo da casa. ${ }^{7}$

Essa perecividade das fotografias nunca retirou dos Xikrin o interesse por elas. A pergunta por elas era das primeiras a serem feitas - como eu estava, a minha família, se havia levado boas miçangas, e em quantidade suficiente para todas, tarefa sempre impossível, e então se havia levado as fotos tiradas na viagem anterior. De novo, o mesmo: um dia vendo, revendo e circulando fotos, comentando, se admirando, admirando os seus, os rituais, as roças, ou o que havia sido retratado na estadia anterior, até o seu derradeiro fim, ao serem descartadas pelas mãos das crianças.

Na realidade, tirar fotos em formato analógico e ampliá-las para a devolução acabou de fazer da antropóloga também retratista. Como demonstro em Cohn (2000), a ornamentação corporal das crianças é especialmente rica e cuidadosa, e excepcionalmente cotidiana - já que adultos só se ornamentam de modo mais completo para eventos públicos, como rituais e reuniões políticas - e, além do mais, são marcas, modos de expressar, promover e mostrar (amerin) seu crescimento e sua aquisição de novas habilidades, como a de andar e falar. Mães e avós logo viram na etnógrafa-fotógrafa uma retratista para registrar esses momentos - e fazer com que este mostrar, amerin, ganhasse potência (Cohn 2019). Neste caso, porém, não só as fotos eram encomendadas, como também as crianças eram preparadas inclusive na pose e no cenário escolhidos, e a encomenda era

7. É interessante notar que, em razão da ênfase que os Xikrin davam à relação de alteridade para a escola, enquanto ela ainda era o espaço do não indígena, do kuben, ou seja, enquanto professores eram ainda não-indígenas (situação que vem mudando apenas de algum tempo para cá), as crianças-alunas jogavam pelas janelas as tarefas do dia, em seu suporte-papel, e a escola estava frequentemente rodeada de papéis amassados; em compensação, a escrita estava nos corpos e nas paredes, em toda parede de alvenaria que houvesse (Beltrame 2013). Do mesmo modo, documentos são devidamente e cerimoniosamente armazenados em casas de lideranças, Agentes Indígenas de Saúde e professores, mas nunca lidos e usados. Até recentemente, para qualquer documento para os não indígenas kuben, mesmo os mais simples, os quais eles teriam plena capacidade de redigir, se demandava a qualquer kuben que o fizesse. Aos Xikrin, o suporte-papel parece não ser interessante - ao contrário do suporte-corpo, mais adequado à escrita, como, aliás, a qualquer adorno, modo mais adequado de tornar escrita kukradjà . 


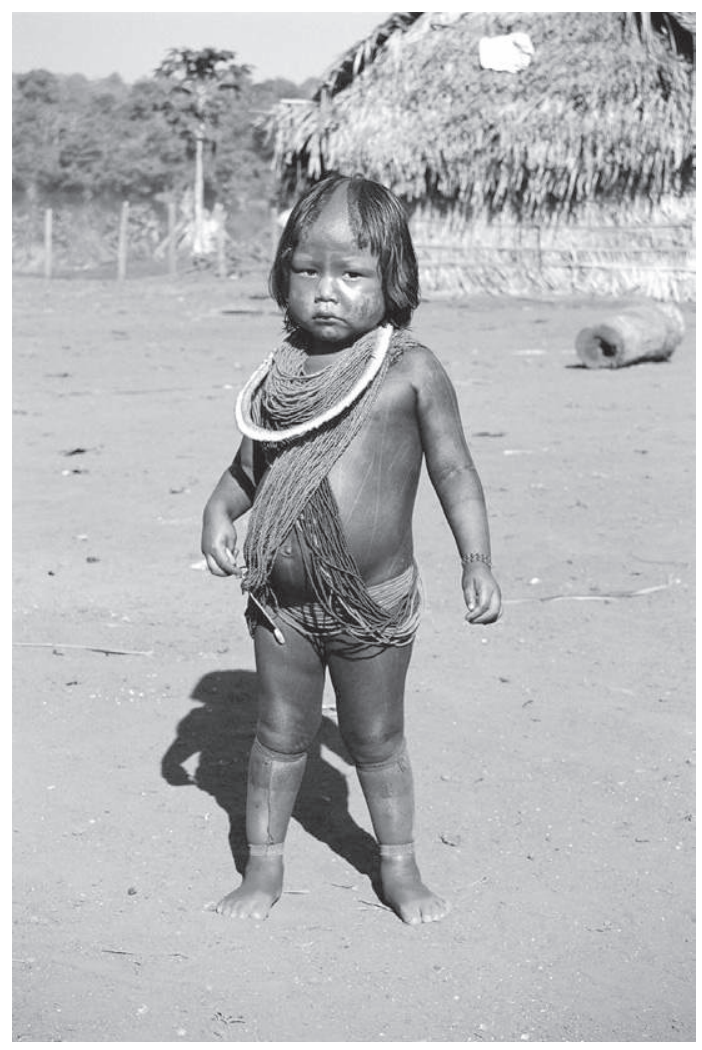

Fig. 1 - Menina xikrin adornada e posicionada pela mãe para fotografia pela etnóloga; aldeia

Bakajá, década de 1990 (foto: C. Cohn)

estendida para uma ampliação maior e emoldurada, as únicas fotos para as quais era planejada uma maior perenidade (Figura 1). Fotos de crianças, o grande foco e o grande mote da vida dos Xikrin e do fazer e se fazer mebengokré.

$\mathrm{O}$ gravador era algo à parte. Ele permitia que o que fosse gravado fosse também imediatamente ouvido, diferente das fotos, que na época demandavam o retorno da antropóloga à sua casa, a revelação e a ampliação das fotos, e só então sua volta no suporte-papel, descartável e logo descartado. Essa particularidade do gravador fez dele uma mídia muito requisitada, e os mais velhos frequentemente me chamavam às suas casas para me contar histórias que deveriam ser registradas no meu "gravadorzinho", o gravador ngrire. ${ }^{8}$ Suas falas eram então ouvidas inúmeras vezes, mas, mais interessante talvez, compuseram um evento especial de aprendizagem de narrativas, já que reuniam uma atenta plateia - normalmente familiar, pois aconteciam nas casas - e que pode ser ouvida nas gravações, pontuando as falas, questionando, sugerindo temas que haviam sido deixados de lado. Igualmente, a cada ritual eu era instada a me redobrar para registrar os cantos no gravador e fotografar determinadas cenas e eventos rituais - coisa que só pude fazer com a ajuda das crianças, que empunhavam o gravador acompanhando

8. Muitas dessas histórias foram transcritas posteriormente por mim e Bekatenti, conhecido por Maradona, a quem muito agradeço, e que sempre me recorda orgulhosamente ter sido meu professor, e compuseram o capítulo 1 de minha tese (Cohn 2005). Este caso é revelador, porque, tratando de histórias de expedições de guerra e das aproximações e dos distanciamentos das equipes de contato e pacificação, cada velho e cada velha (mebengêt), ouvindo uma versão, quis dar a sua, tornando o conjunto cada vez mais rico. 
cantores e cantoras, enquanto eu me empenhava em fotografar os inúmeros eventos simultâneos que um ritual xikrin apresenta, sempre guiada por eles. ${ }^{9}$

Mais do que a câmara fotográfica - que exigia outras habilidades, rolos de filmes e laboratórios de revelação e ampliação que não estavam ao seu alcance -, os gravadores passaram logo a ser inseridos nas listas de demandas de presentes, junto com miçangas, roupas, chinelos, mosquiteiros, para quando de meu retorno. Em especial, o finado Kuprore, que tantas histórias contou, o pedia para seu neto (DS), Patukre, que se encantou com o equipamento (Figura 2). A cada viagem, novos gravadores, porque eles se revelaram tão perecíveis quanto tudo o mais. ${ }^{10} \mathrm{E}$ uma quantidade inesgotável de fitas e pilhas para que pudessem funcionar durante minhas ausências. Afinal, gravar rituais eles faziam já há algum tempo, mas com enormes gravadores de fita $\mathrm{K} 7$ carregados nos ombros - modo de registrar seu kukradjà e importante meio

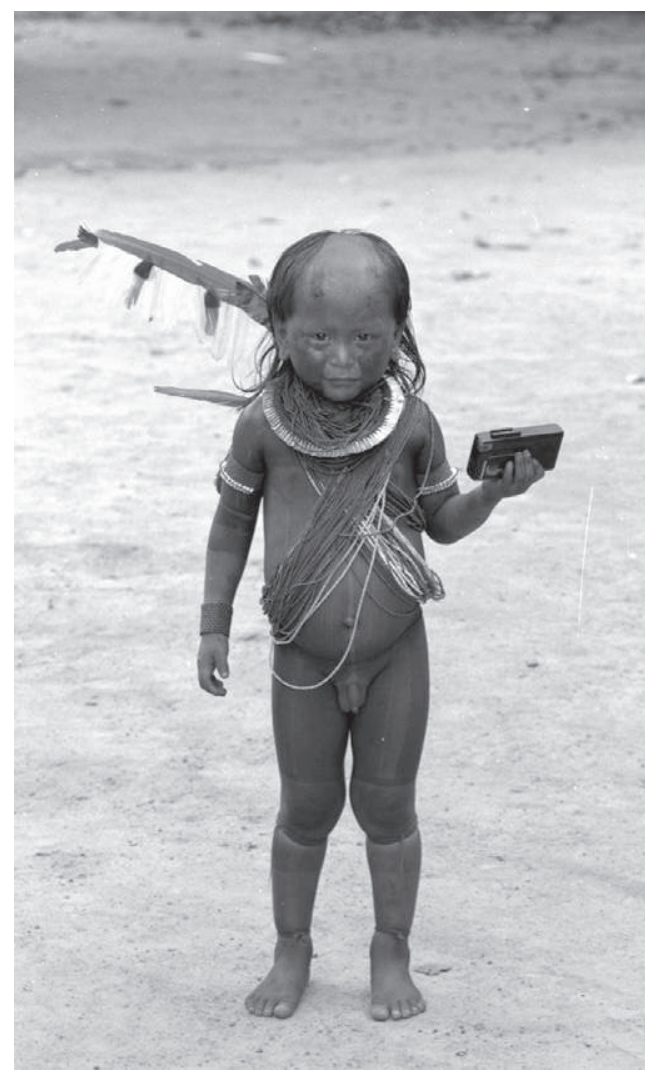

Fig. 2 - Menino Xikrin posa para foto com o gravador que pediu à etnóloga como presente; aldeia Bakajá, década de 1990 (foto: C. Cohn)

9. Na realidade, tinha que me desdobrar ainda em outro papel, porque em muitos desses momentos precisava estar presente como dançarina também.

10. Álvares (2018, p. 126-127) comenta essa relação com objetos não-indígenas quanto aos Maxakali, marcada também pelo descarte quase instantâneo, e que remete muito ao caso dos Xikrin; Ewart (2012) comenta como as miçangas são o único material realmente reutilizado pelos Panará, como também pelos Xikrin. Lembramos que adornos pessoais são descartados quando da morte, e tudo sempre foi descartado e descartável para os Xikrin, o que torna os produtos industrializados uma questão (Vidal 1977). Turner (1993) discute outro uso, menos interno, pelos Kayapó, também Mebengokré, dos registros, voltados à imagem pública e a um uso político. 


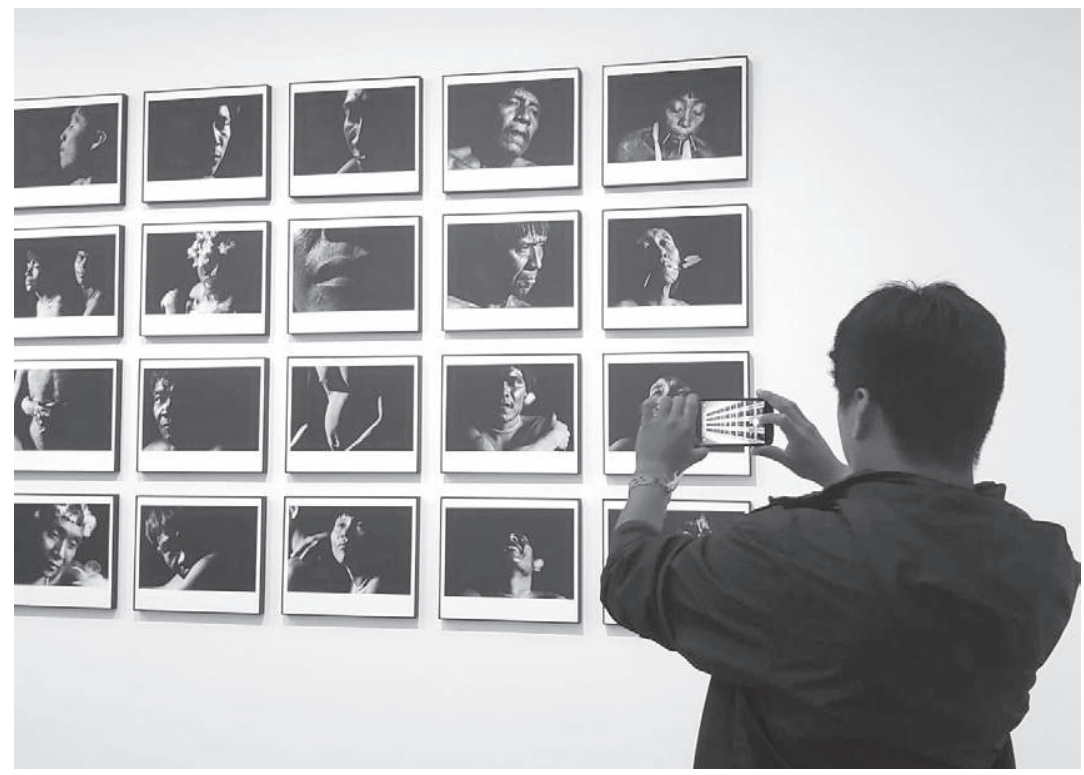

Fig. 3 - Bep-nat Xikrin registra a visita à exposição de Claudia Andujar sobre os Yanomami em São Paulo, janeiro de 2019 (foto: C. Cohn)

de aprendizado - e meus pequenos gravadores, logo assim referidos, lhes pareceram especialmente valiosos. ${ }^{11}$

Assim se fez uma coleção particular e amadora de registros em áudio e fotos - que, décadas depois, eles se interessaram em rever, pela iniciativa dos jovens, que queriam se ver "quando eram crianças", foco principal desse meu início de registros, razão de minha primeira pesquisa, como aludi anteriormente. E foi também assim que eu comecei a planejar esse retorno - o que fiz pela digitalização e a apresentação do material em cada aldeia, com um projetor, um telão e caixas de som, e debatendo o modo de retorná-los, definitivamente, às aldeias (Figuras 4 e 5). Essa experiência, porém, com toda a sua beleza e com toda a satisfação que é para uma antropóloga ver seu material apreciado e valorizado pelas pessoas com que trabalha - o que tem dado um novo sentido ao próprio material aos olhos da pesquisadora -, é pautada por dilemas. Dentre eles, questões como a apresentação pública da imagem e das vozes de pessoas falecidas, que não devem mais ser vistas, ouvidas, ou mesmo referidas pelos nomes, e que reativa o luto de seus parentes, gerando potencialmente muita dor. Eu me apoio neste ponto para aqui comentar o mal-estar de uma antropóloga em atividades assim.

11. Desnecessário, talvez, dizer que atualmente a demanda por celulares como presente cresceu enormemente, assim como o registro feito por eles com essa mídia (Figura 3). 
Retornando sua coleção de material audiovisual: os dilemas de uma antropóloga

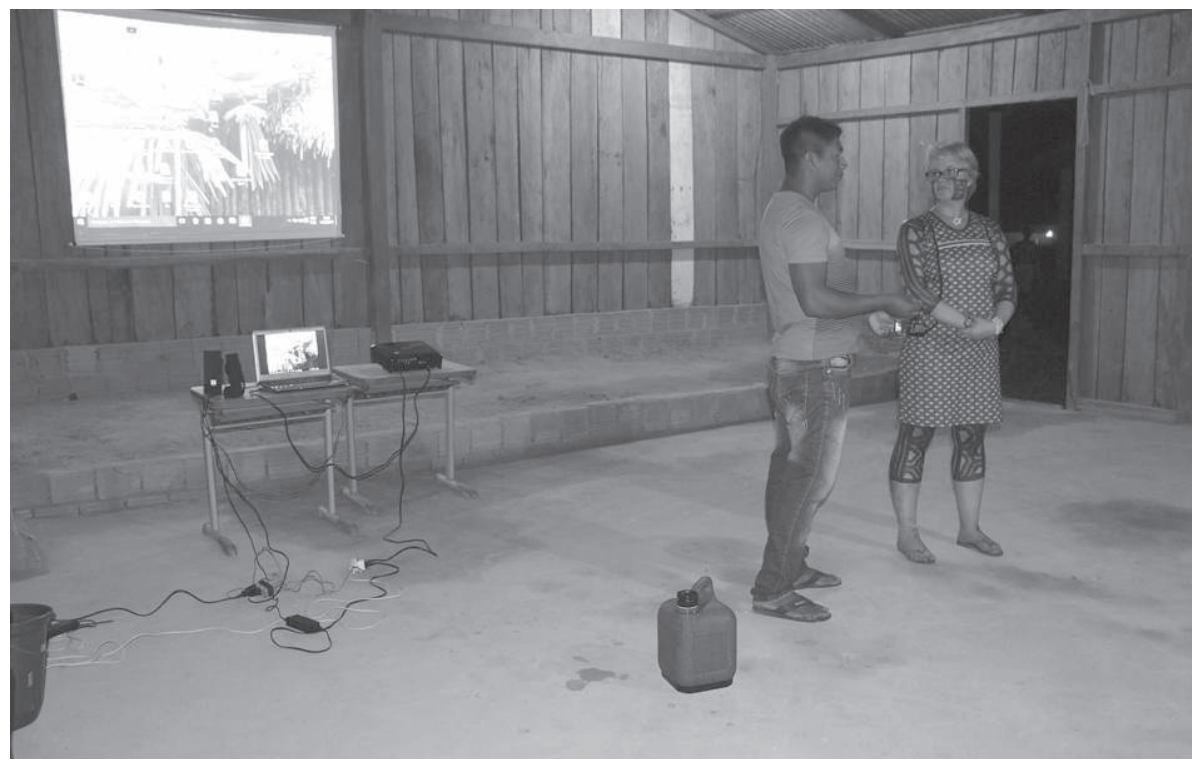

Fig. 4 - Takàk-jakare (Koka) Xikrin e Clarice Cohn apresentam a coleção de fotos a serem mostradas na aldeia Krãhn, 2017 (foto: Camila Boldrin Beltrame)

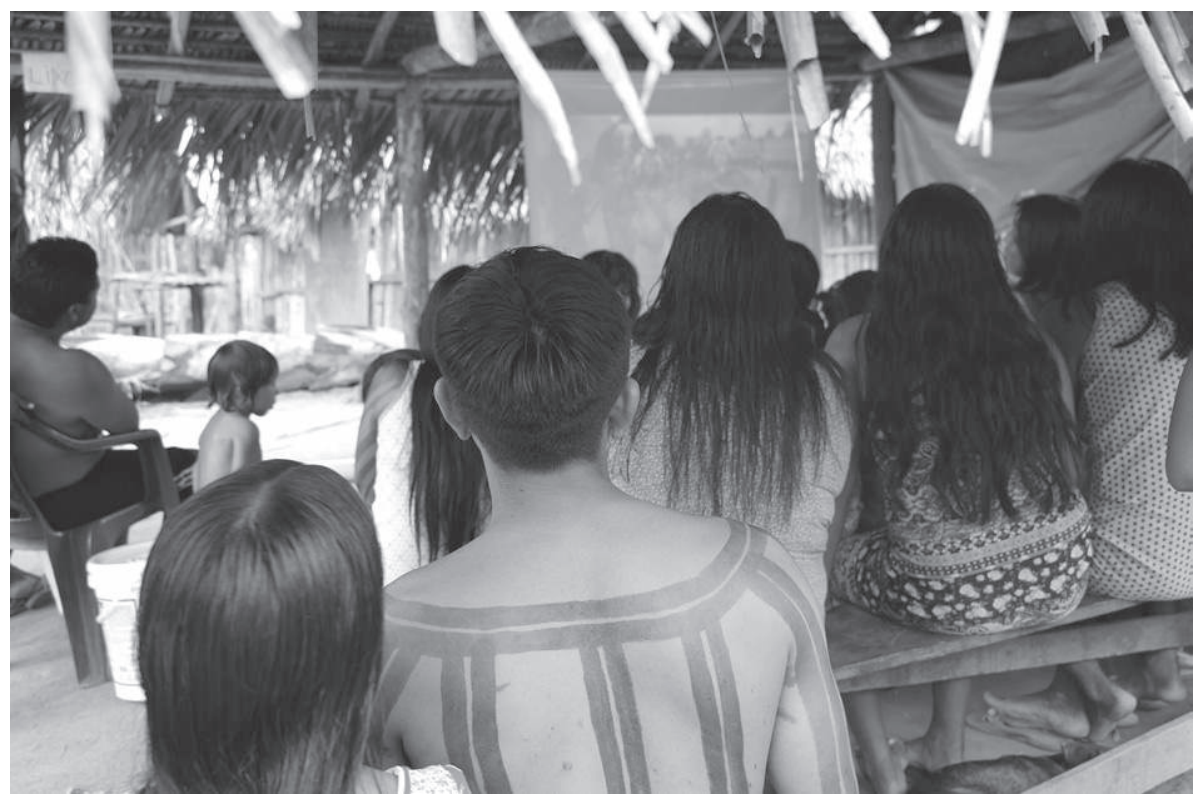

Fig. 5 - A audiência xikrin das "fotos de antigamente" na aldeia Prin-djãm, 2017 (foto: Camila Boldrin Beltrame) 


\section{Um desconforto: 0 registro de pessoas falecidas}

São comuns as análises antropológicas que apontam para despropósitos interculturais em experiências deste tipo realizadas por pessoas que não são antropólogos. Mas o que dizer quando quem as propõe é antropóloga, como eu? Porque, sugiro, os desencontros são inevitáveis, embora, às vezes, sentidos agudamente pela antropóloga, mesmo se previsíveis. Assim, sabe-se que não é bom reavivar os mortos através de suas imagens e vozes, ${ }^{12}$ mas ao mesmo tempo os próprios Xikrin, nesta experiência, gostariam de poder ouvir cantos que um grande cantor já falecido gravou, ou rever importantes rituais que ficaram na memória e foram registrados em fotos em que pessoas falecidas estão presentes. Como resolver dilemas como este? Evidentemente, a única resposta válida será resolvê-los no diálogo com eles, mas isso não oblitera o fato de que a própria necessidade do diálogo gera e explicita a tensão criada por este retorno dos materiais.

A morte, para os Xikrin, exige uma separação definitiva. Parentes mortos são sempre um perigo e, solitários e saudosos, estão constantemente desejando voltar a se relacionar com os vivos - e isto significa trazê-los para seu convívio, ou seja, tornar os vivos mortos. O luto é um longo processo de separação e quitação dessa relação, processo esse que se inicia com o risco iminente, quando os mortos, aparentemente ainda descrentes de seu destino, permanecem próximos dos lugares onde viveram e trabalharam - é comum ouvi-los ainda "mexendo" (kupêi) nos seus instrumentos de trabalho, andando pela casa. Os enlutados cortam os cabelos, deixam de se pintar - uma das duas únicas razões para uma pessoa não portar a pintura corporal, sendo a outra a doença -, falam baixo, praticamente sussurrando, ou falam o menos possível, obedecem a uma série de restrições alimentares e ficam em casa, na sombra. O luto só termina, em tempos determinados para cada caso, quando um parente dos enlutados sai para uma caçada que, com o consumo da banana, retorna aos enlutados a comida dos vivos e os retira do isolamento (Cohn 2001a, 2010).

$\mathrm{O}$ enterro, hoje feito em cemitérios próximos às aldeias, antigamente feito em duplas exéquias (Vidal 1977; Verswijver 1992), busca tornar o recém-morto o mais confortável possível. Enterrado com todas as suas posses, ornamentado, enquanto a carne putrefaz, até sobrarem apenas os ossos, sua tumba é mantida

12. Quando, na década de 1990, Bekatenti me pediu para ajudá-los a organizar uma formação em produção de vídeos, entrei em contato com então CTI e o nascente Vídeo nas Aldeias. A resposta que tive foi a de que não fariam mais oficinas com os Xikrin do Bacajá, porque os vídeos produzidos em oficinas com os Xikrin do Cateté e que para lá teriam ido - vídeos que eu nunca cheguei a ver, em fitas VHS - teriam sido mal cuidados, deixados mofar e descartados. Quando perguntei aos Xikrin sobre esses vídeos, eles me explicaram que tinham tido que descartá-los porque neles aparecia uma grande liderança recentemente falecida, e que, ao vê-los, as mulheres todas iniciavam um choro ritual coletivo. 
aquecida por um fogo preparado e conservado pelas mulheres. As comidas - ou o leite do peito ou mesmo o soro para a diarreia, quando a criança é muito pequena (Cohn 2000, 2010) - são também sempre renovadas. Isto lhe dará forças para seguir viagem, uma viagem longa e cheia de obstáculos, para cumprir seu novo destino, no qual se encontra com os outros mortos, que o recebem com o choro ritual - o mesmo com que se recebem em vida parentes que retornam depois de longas ausências (Vidal 1977, 1983; Lea 2007).

Mas esse destino é incerto. Vidal (1983, p. 317) sugere que "a morte entre os Kayapó não é motivo de grandes ritos ou de elaboração conceitual mais abrangente e, sendo assim, não chegou a suscitar maior interesse por parte dos antropólogos". Isto é parcialmente verdade, mas, se compararmos com o rendimento analítico para os Krahô (Carneiro da Cunha 1978), somos levadas a concordar com Vidal. Pouco se fala sobre pessoas falecidas, e pouco se fala sobre seu destino. Ao contrário, ter que falar de pessoas falecidas é reviver a perda e motivo de novos choros rituais. Desde meus primeiros momentos de pesquisa, chegando em uma aldeia em que as perdas tinham sido grandes e recentes em função das doenças advindas dos não-indígenas e pela aceleração das guerras que aconteceram então (Fisher 2000; Cohn 2005), a maior parte dos mais velhos tendo perdido cônjuges, irmãos, pais, filhos, eu me vi praticamente impossibilitada de fazer um censo demográfico por conta dessa rememoração, e para respeitá-la.

Os mortos são ditos mekaron, porque eles são só karon $^{13}$ - uma parte da pessoa que é a única que resta após a morte, sendo o corpo consumido pela terra e seu kukradjà, tendo sido suas prerrogativas rituais, como as chama Lea (2012), e seus nomes repartidos por parentes que nasceram quando ainda vivia. O karon, aliás, é o único componente da pessoa para o qual não se tem uma explicação de onde vem e como nela se fixa - o corpo sendo feito pelo sêmen dos pais e no útero, e com o sangue da mãe, nomes e prerrogativas sendo transmitidas entre gerações. De fato, a fixação do karon na pessoa é um processo longo, e a criança nova está sob o constante risco de perdê-lo, ou dele se afastar de seu corpo (Giannini 1991; Cohn 2000, 2001a). O karon também é o que dá a capacidade onírica, ou melhor, é ele quem viaja quando o corpo dorme, tendo experiências e reencontrando pessoas nesses momentos. O roubo do karon por diversos seres, mas em especial pelos mortos (mekaron), é algo que só pode ser remediado pelo wajangá, ou os xamãs, em uma extensa e difícil negociação (Vidal 1977; Giannini 1991). O único momento em que os mekaron retornam às aldeias e ficam próximos dos vivos é quando dos rituais, o que os torna perigosos, mas também mais potentes (Cohn 2000).

13. O prefixo me indica um coletivo; os mortos são sempre referidos em sua dimensão coletiva, como mekaron. 
A morte é marcada pelo tratamento do corpo, que recebe uma ornamentação cuidadosa (Cohn 2010), e pelo choro ritual das mulheres que, como argumenta Lea (2007), é o equivalente da oratória masculina, e feita apenas pelas velhas (os homens, como os(as) jovens, também choram, mas apenas vertendo lágrimas, e em silêncio). ${ }^{14} \mathrm{O}$ choro, altamente formalizado, fala da pessoa falecida, de seus feitos e da impossibilidade de se reencontrarem, a não ser na morte - diferente daquele com que se recebe parentes vivos, em que se fala de saudades, mas se celebram a relação e a vida. Em um primeiro momento, o choro ritual é quase privado, discreto, a mulher se aproximando de sua casa e, no seu exterior, chorando - um choro cantado - baixinho, cercada por suas parentas mais novas, com um olhar atento e cuidadoso, vertendo lágrimas silenciosamente. Ele irrompe de modo verdadeiramente espetacular quando do enterro, quando as mulheres choram a plenos pulmões e agarram qualquer coisa cortante que esteja à mão para cortar suas cabeças, dizendo querer morrer e acompanhar aquele que as deixou. Este choro é também verdadeiramente contagioso, e toda mulher mais velha é relembrada de suas perdas, disputando materiais cortantes para acompanhar seus choros e também se baterem. Os Xikrin dizem sempre que este momento pode levar, se não controlado - o que demanda o esforço de muitos - à morte da enlutada, que durante o enterro está com o rosto marcado pelas lágrimas e pelo sangue que escorrem. ${ }^{15}$ Portanto, qualquer rememoração da morte e dos mortos pode levar a momentos assim, o que obviamente deve ser evitado por todos.

Pensando nisso, quando preparei para a viagem de apresentação nas aldeias o material, retirei do seu corpus todas as imagens de pessoas falecidas, e selecionei áudios protagonizados apenas pelos vivos. ${ }^{16}$ Mas isto não eclipsou o fato de que, como eles sempre souberam, por terem acompanhado (ou, como diziam, guiado) minhas atividades de registro, eles existiam. E eram continuamente demandados - todos queriam rever seus parentes falecidos, para "matar as saudades" (kum owama kêt), me diziam. Assim, na primeira dessas apresentações, justo na Casa de Saúde do Índio, em Altamira, em que se encontravam muitos Xikrin que eu

14. Como argumento em outro trabalho (Cohn 2000), a prática de aprendizagem é contínua para os Xikrin, mas marcada por um momento próprio para se expressar.

15. Ver Lea (2006) para uma descrição deste evento.

16. Foi neste trabalho preparatório que contei com o auxílio de Bep-tô, Tekàkdjy e Takàkjakare, imprescindível por conhecerem melhor as suscetibilidades envolvidas - porque às vezes não precisa ser a imagem ou a voz da pessoa a se cuidar, mas a de um ritual que era sua prerrogativa, por exemplo. Porém, como já havia acontecido em um primeiro momento com o gravador, depois com a câmara digital, também o computador, que continha todas as fotos, foi logo apropriado por eles, que passaram a selecionar as fotos que queriam guardar, já sem a minha mediação. Em uma viagem recente, minha orientanda Jucimara Cavalcante foi instada a gravar em seu computador uma seleção dessas imagens feita por eles, e apresentá-las pelas aldeias. Quando as revimos juntas, descobri haver muitas fotos de pessoas falecidas que eu tinha tido o cuidado de não mostrar. 
não queria excluir dessa atividade por estarem distanciados das aldeias onde as apresentações iriam acontecer - lugar especialmente marcado pela morte e sua iminência - fui persuadida por eles de que não haveria problema em mostrar todo o material, já que eles acharam o conjunto preparado por mim e pelos Xikrin muito curto. Embora argumentasse que preferia não fazê-lo, porque não queria gerar sofrimento, acabei por ser persuadida pela insistência deles de que estavam preparados para tal e "que nada de mal iria acontecer", mas que acabou por gerar, como havia previsto e temido, sofrimentos variados, embora naquele momento contidos. O que mais me marcou foi ver um velho, o kubengêt Tàpiet, se afastando, silencioso, e chorando baixinho em um canto da sala que dispuseram para a apresentação. Eu me prometi nunca mais ser persuadida a fazê-lo. Não o fiz mais, em público, e ainda em Altamira preparei uma pasta de fotos que chamei de metihn, os vivos, para poder mostrar quase o conjunto todo de fotos, retirando apenas as fotos de falecidos. Desisti da apresentação mais curta preparada, que pensava dar apenas uma ideia do conjunto das fotos, para pensarmos juntos como e em que mídia e com que tratamento retorná-las definitivamente mais tarde.

Mas, ainda nas aldeias, tive que responder a demandas diversas de parentes que queriam ver ou ouvir - "só entre nós", me diziam - seus entes queridos já falecidos. Na maior parte das vezes, consegui evitar, em especial as demandas de ver imagens de falecidos recentes. Mas novamente, no caso de um velho que muito me acompanhou durante as pesquisas, o kubengêt Kuprore, já mencionado, me deixei persuadir por sua filha a gravar para ela as fotos do pai, que ela veria em sua televisão, sozinha - só para ouvir, de minha rede, o choro que brotava, à noite, de sua casa, com uma dor indizível em meu coração.

No ano seguinte, um homem de minha idade me pediu para gravar para ele os áudios do pai, o mesmo Kuprore, argumentando que não havia podido aprender tudo o que teria querido com ele em vida, e que as fitas poderiam ajudá-lo. ${ }^{17}$ Eu concordei, mas fazendo com que me prometesse que não mostraria os áudios para sua mãe, que já andava sonhando com o falecido cônjuge - e sonhar é um reencontrar, é o momento em que o karon viaja e tem experiências enquanto o corpo dorme - e já estava, me parecia, se preparando para a sua ida. Não tenho como garantir que ele tenha respeitado o meu pedido, mas sei que ele por diversas vezes agradeceu os áudios e disse ter matado as saudades do falecido pai, e aprendido muito com os cantos e as narrativas plasmadas em áudio.

Ao lado das muitas belezas geradas por essas apresentações, como o encantamento de ver os grandes rituais feitos em tempos recentes, quando moravam, antes de Belo Monte, na mesma aldeia, o vigor de corpos e ornamentos, a beleza da própria aldeia, e nossa juventude, a minha inclusive, assim como o

17. As analogias com a experiência de Laura R. Graham (2018) são impressionantes neste sentido. 
encantamento dos jovens em se verem crianças, esse processo, por mais avisada que esteja a antropóloga, não pode deixar de ser pautado por sofrimentos.

\section{Outro desconforto: a publicização de conhecimentos que não são públicos}

Os regimes de conhecimento, modos de produzir, circular, obter, consumir conhecimentos, têm sido pautados pela análise recente da antropologia (Carneiro da Cunha 2009; Coelho de Souza e Coffaci de Lima 2010; Carneiro da Cunha e Cesarino [orgs.] 2016). Para os Xikrin, o conhecimento é sempre aberto, e está sempre em aberto. A começar porque demanda uma provisão contínua de novos conhecimentos, que vêm dos outros, ou das relações de diferença, como as chamei (Cohn 2005). Em aberto também porque concebem a aprendizagem como algo a ser construído por cada um, a partir de seu interesse, e por meio de pedidos (kukiere) para conhecedores, mais diretos ou mais mediados, constituindo-se assim em uma multiplicidade de conhecimentos e conhecedores que têm sempre um fragmento do que seria um conhecimento total, sempre pessoal. Este é, de fato, o oposto da transmissão de conhecimentos como um corpus total e totalizante, ou seja, traz em si a marca da diferenciação, que é, como tenho argumentado, o que define o kukradjà (Cohn 2005): termo polissêmico, por vezes traduzido por cultura, e que abrange os meios de se fazer mebengokré e o que é reconhecidamente mebengokré ou, como sugiro, tanto produto como processo.

Mas isto nos coloca, neste caso, um novo problema: o fato de que o conjunto das fotos propunha, à revelia da antropóloga, uma versão daquilo que é registrado que se poderia tornar homogênea ou única. A demanda por registrar seu kukradjà levava ao risco de propor uma visão, momentânea mas total, potente pelo registro, temporalmente marcado, do que fosse uma totalidade. Este é um problema sobre o qual venho advertindo também no sentido das experiências de escolarização indígena - as escolas tendo como público todas as crianças, que aprendem simultaneamente tudo que lhes é ensinado; o problema se agrava com as propostas de se ensinar "a cultura indígena" na escola, e para lá levar conhecedores como mestres escolares (Cohn 2016). Se isto, por um lado, pode ter em alguns lugares resultados interessantes - veja-se a diferença da relação das escolas entre os povos do Maranhão na década de 1990, alguns se voltando aos conhecimentos não indígenas que as escolas possam trazer, outros ao "resgate da cultura" (Cohn 2001b), ou o fato de que os Tupinambá de Olivença fizeram da escola o meio para torná-los "fortes na cultura" (Santana e Cohn 2016, 2018) -, por outro lado, é capaz de gerar um caráter homogeneizador, o oposto do que tenho visto entre os Xikrin e aprendido com eles.

Os Xikrin estão, depois de décadas deixando a escola para que as crianças experienciem a relação com os não-indígenas (Cohn 2005; Beltrame 2013), passando a assumir suas escolas como professores. Ainda não sabemos quais serão os efeitos disso, em especial nesta questão sobre como o kukradjà nela 
entrará, e como os professores lidarão com este tema. Mas as propostas de tornar os registros produzidos por mim em materiais escolares, muitas vezes demandado por eles nas nossas atividades, além de trazer o problema anunciado acima, de como lidar com importantes eventos em que falecidos aparecem, me anunciava esse outro risco.

Mas havia outro ponto importante: sendo a retratista e a gravadora do kukradjà, muitos desses conhecimentos que não são de todos (os me 'õ nhõ kukradjà, os conhecimentos/as prerrogativas de alguém, em oposição a me kuni nhõ kukradjà, os conhecimentos que são de todos, ou apenas me kukradjà) estavam registrados em minhas fotos e em meus áudios, assim como coisas que não devem ser vistas por todos e estão nos registros - como a confecção das máscaras chamadas Mekaron tire ${ }^{18}$ feitas no mato pelos homens, longe dos olhares das mulheres e das crianças, que só os veem já em ação, ou das máscaras para o ritual $B \hat{o},{ }^{19}$ confeccionadas no único momento em que a casa central é fechada por palhas de modo a impedir a visão de seu interior por mulheres e crianças. Cantos que são apenas de algumas pessoas, relativos à sua atuação ritual, estão gravados. Retornar todo esse material aos Xikrin não seria fazer de outro modo o que eu mesma vinha denunciando como o risco da escolarização das crianças xikrin?

Desconfortos: a pergunta fica em aberto e, evidentemente, aqueles que a responderão serão os Xikrin. A proposta é desenvolver um trabalho conjunto de análise do material, que reúna jovens e velhos, homens e mulheres, para avaliar o que deve ou não ser publicizado. A viabilização desta proposta - tanto financeira e logística, mas principalmente política, quanto à decisão do que seria próprio fazer, de modo a respeitar o kukradjà de cada um, e do que não pode ser visto por todos - é ainda uma questão.

\section{Uma redescoberta: a beleza e a alegria}

Mas as fotos trouxeram também outro efeito: o da redescoberta de uma certa beleza que é mais afeita à imagem que têm de si mesmos, e bastante diversa da que apresentam hoje. Em 1992, objetos e alimentos industrializados já eram muito comuns nas aldeias, e as roupas, bastante usadas. Mas, atualmente, como consequência de muitos dos processos vivenciados há um maior consumo de roupas, sandálias e alimentos não indígenas. A maior demanda de compensação pelos impactos do aproveitamento hidrelétrico é a de bens, como artefatos para

18. Ver Cohn (2000) para uma análise deste ritual. O termo mekaron, no texto em maiúscula, se refere à máscara, ou à sua dimensão imagética, sendo todas as máscaras, assim como a sombra, e as imagens em fotografias denominadas karon ou, no coletivo, mekaron. Tire significa grande, portanto, as máscaras e o ritual em que dançam com elas são referidos como "Grandes Máscaras".

19. Ver Vidal (1977), Cohn (2000) e Tselouiko (2018) para descrições e análises desses rituais. 
rituais, em especial miçangas (em nome de "projetos culturais"), instrumentos agrícolas, de pesca e caça (em nome de "projetos de atividades produtivas"), casas de alvenaria, caminhonetes (em nome de "acessibilidade", com os rios tendo se tornado inavegáveis e os Xikrin passando a viver a era da "Amazônia das estradas" [Tselouiko 2018]), e programas de transferência de renda (como o Bolsa Família e o salário maternidade), além dos cargos remunerados que permitem às famílias acesso a esses bens. ${ }^{20}$ Visualmente - e lembremos o valor de ver e ser visto para os Xikrin -, as pessoas e as aldeias, assim como a Terra Indígena, estão muito diferentes hoje.

Os jovens, que tinham encabeçado a proposta e eram os principais demandantes deste retorno de meus registros, logo começaram a chamar as fotos apresentadas de mekaron tum, ou fotos velhas, ou antigas, ou amrebê kam mekaron (ou as fotos dos tempos antigos), ou me tum-re karon (as fotos dos antigos). Para eles, as fotos mostravam, efetivamente, outros tempos, mesmo que tivessem apenas 20 ou 30 anos. Para eles, eu hoje, oficialmente, sou uma "velha", uma kubengêx, já que a categoria de idade com a qual compartilho o cotidiano tornou-se mebengêx, por serem já avós. ${ }^{21}$ É absolutamente coerente, para estes jovens, que a kubengêx traga fotos de antigamente (amrebê), como os velhos em geral contam histórias de antigamente. E foi nesse registro que viram minhas fotos e ouviram os áudios que eu tinha para mostrar. Isso gerou encantamento e reflexões, mas também um mal-entendido. Como sempre, enquanto eu ia subindo o rio e fazendo as apresentações do material com a equipe já referida, as notícias iam sendo transmitidas pelos rádios das aldeias - e a expectativa de ver esse "material de antigamente" aumentava a cada parada e a cada narrativa pelo rádio. Desconfio que o caráter "de antigamente" também foi aumentando e, na última aldeia, Ràp-kô, um casal de velhos (estes, da categoria dos "mais" velhos), Tedjere e Irepron, se acomodaram com antecedência e expectativa para ver as fotos; no entanto, quando começou a apresentação de slides, me chamaram, frustrados, para tirar uma dúvida: afinal, esperavam ver fotos de tempos realmente antigos, de quando viviam andando pela floresta, de quando não usavam roupas, o que fora vivenciado por eles, fotos em preto e branco que, me contaram, um padre um dia lhes tinha mostrado. Foi preciso

20. Ver Gordon (2006) para uma discussão do processo vivenciado pelos Xikrin do Cateté a partir da indenização da então Companhia Vale do Rio Doce.

21. Para uma análise de como se definem as categorias de idade pela vida das pessoas, ver Cohn (2000, p. 61). As passagens na vida da criança se dão pelas expressões de certas habilidades que apresentam, como andar, falar e comer autonomamente; ter crianças é o modo de deixar de ser criança; e não ter mais filhos (passando essa responsabilidade a seus próprios filhos, como me explicou uma vez Ngren-tô, em uma linda imagem xikrin de continuidade) é passar a ser velhos. Estamos, hoje, na categoria de velhas por sermos (no meu caso, por extensão) avós, mas das mais jovens entre as velhas, digamos, que são, estas sim, as que são "só" avós, não gerando mais filhos. Vidal (1976) fez uma primeira e seminal análise do tema. 
conversar para concordarmos que, sendo os três velhos, mebengêt, as minhas fotos só poderiam ser, digamos, de nosso tempo em comum de juventude. Para meu deleite, eles passaram então a realmente apreciar o que viam.

Isto nos coloca a questão do que é "de antigamente". Uma questão clássica, já debatida em termos de uma "amnésia genealógica" (Gow 1991), ou mnemônica, dos ameríndios. Este "de antigamente", devemos assumir, é tão amplo quanto o é o kukradjà, e relativo. Relatos que são "de antigamente", por serem dos tempos em que o mundo e a vida tal como ela é se formaram, são tão presentes quanto quaisquer outros - e o homem que subiu ao céu após uma briga com sua mulher e fez o trovão e as tempestades até hoje trovoa nos céus: os trovões de cada tempestade não são seu produto, mas ele mesmo trovejando. E o que ficou para trás, a mobilidade, as comidas, é sempre potencialmente relembrado e revivido. ${ }^{22}$

O interessante é notar que, aos olhos dos jovens, este "de antigamente" lhes apresentou uma imagem de si como outros. Seus comentários, para além das risadas por se verem e aos amigos e parentes quando crianças, banguelas etc., lhes apresentou um modo, digamos, mais mebengokré do que o atual. Afirmavam sempre a maior extensão da tonsura - os jovens hoje têm vergonha da tonsura mebengokré, os rapazes usando os cabelos curtos e não mais fazendo o iokó, a raspagem do cabelo, a não ser excepcionalmente para alguns rituais. As jovens kurerere, que estão em idade de se casar, têm em sua maioria se recusado ao kum iokó, e todos atualmente raspam uma risca bem menor, e mais discreta, de seus cabelos. Comentavam a liberdade das crianças brincando desnudas pelas aldeias; a beleza das festas, feitas em uma aldeia só, cheias de gente, e com materiais para a ornamentação majoritariamente vindos da floresta; a beleza das pinturas corporais; e a alimentação provinda de roças, da coleta e da caça.

Isso lhes dava uma dupla sensação: a de perda, de estarem, talvez, sendo menos mebengokré, e outra de ganho, das riquezas que puderam obter nos últimos anos. De um lado, uma admiração pelos mais velhos; de outro, pelas suas conquistas, porque, afinal, a vida lhes parece agora mais fácil, não tendo que se arriscar nas guerras, arrancar árvores com os braços, podendo usar a espingarda ao invés da borduna, tendo provisão de alimentos mesmo quando estes escasseiam ao se contar apenas com os recursos da Terra Indígena, como a pesca na época das chuvas. Ora, isto me parece absolutamente coerente com o que descrevi e analisei como a definição mesma de kukradjà: algo que deve ser mantido, mas que, para tal, deve ser continuamente modificado.

22. Algo tem me saltado aos olhos atualmente e pode ilustrar o que digo: depois de décadas de luta para obter aldeias de alvenaria, nos últimos anos elas têm sido parcial ou totalmente abandonadas, com famílias se mudando para outras aldeias - refazendo um movimento que sempre fora o deles (ver Cohn 2005) - mas também abrindo novas aldeias, que são, e têm o layout, de acampamentos na mata. Idealmente, esse ar de acampamento seria temporário e breve, cedendo lugar a uma nova aldeia de alvenaria, mas o movimento parece não cessar, e logo uma nova aldeia surge, com casas de palha espalhadas nas primeiras roças abertas em um novo local antes por eles não habitados. 
Para não ficar, então, só no lado negativo da experiência, mas apontando para a necessidade de refletirmos sempre e de modo cuidadoso sobre os dilemas desses processos, mesmo quando protagonizados por antropólogos, fecho com um comentário. Se, ao longo de minha pesquisa, pautada pelo estudo da infância e seus cuidados, foco de minha dissertação (Cohn 2000), as crianças sempre me pediram para tirar suas fotos, e as mães as ornavam para o registro fotográfico, agora me pedem: "tire a minha foto - ou de meu(minha) filho(a) - para que eu - ou ele(a) - possa me(se) ver, quando for adulto, como era quando criança". Sendo assim, o retorno das fotos - que, lembro, segue uma prática que sempre mantive, já que cada retorno a campo sempre foi um retorno também das fotos e dos áudios feitos no campo anterior - gerou uma maior, e diversamente qualificada, demanda por mais registros, e mais retornos. Apesar dos dilemas envolvidos no processo, vividos tanto por mim, a antropóloga, quanto por eles, essa nova mídia simultanemaneamente os obriga a se defrontarem, por um lado, com o luto e a perda, mas, por outro lado, permite que se reencontrem com a beleza e a potência sempre transformada de seu kukradjà.

\section{Conclusões: ameaça ou potencialização do kukradjà?}

O simpósio que instigou esta análise provocava uma questão: se a repatriação digital de conhecimentos indígenas tradicionais seriam uma ameaça ou um bem (ver nota 1). Este texto difere da maior parte das análises que se costumam fazer sobre o tema, voltadas a processos em que indígenas redescobrem objetos e técnicas em acervos museográficos de diversos tipos. Trata-se de algo mais modesto e localizado, o retorno do acervo, amador, diga-se de passagem, enquanto técnica de registro e sua sistematização, de uma antropóloga para o povo indígena com o qual convive ininterruptamente há décadas.

Mas ele pode nos permitir endereçar esta questão a partir do reencontro dos Xikrin com um certo "tempo de antigamente", e as reflexões que isto tem trazido. Para isso, temos que retomar a noção de kukradjà. Como tenho argumentado, ele tem sempre que ser modificado para manter seu potencial, e sua potência está na produção contínua de novas pessoas e coletivos belos e fortes, na sua capacidade de diferenciação. No entanto, nas últimas décadas, tem crescido o temor de que essa maquinaria de diferenciação e de potencialização do kukradjà seja levada ao seu limite - temor compartilhado pelos Xikrin do Cateté (Gordon 2001) -, de tal modo que ela leve apenas à indiferenciação, enfraquecendo os meios pelos quais sempre se produzem novas e belas pessoas e kukradjà, e anulando sua potência (Cohn 2005, p. 178). Este risco, de passarem a ser apenas capazes de produzir versões enfraquecidas de si mesmos, como explicitado de diversos modos por Bep-tok (Cohn 2005, p. 67), de perder essa capacidade, veio à tona na ambivalência dos olhares sobre as fotos (mais do 
que no ouvir os áudios), um olhar de si mesmos como outros, mais ou menos potentes, a depender da ênfase dada a essa peculiar alteridade.

Essa reflexão, devemos dizer, não foi levada por esse processo, e está com eles desde que os conheço. Mas ela foi, sim, levada, de outro modo, para eles a partir dessa experiência. E tem rendido ainda novos olhares e novas reflexões. Não sabemos ainda se alguma logística possibilitará a sua preparação em materiais didáticos ou para o acervo de um Centro Cultural, um projeto que eles têm em grande conta, e que deveria mostrar à cidade de Altamira seu kukradjà. Com isso, não sabemos se o risco de indiferenciação (os termos do seu temor) ou de homogeneização (em meus termos) poderá acontecer, ou se agudizar, ou inversamente se a maquinaria de diferenciação poderá se potencializar nesses espaços institucionalizados, nem ainda quais poderiam ser os guardiões dos materiais para gerir a quem eles podem e devem ser mostrados. Mas devolvidos eles literalmente estão.

Na viagem de 2017, levei pendrives para deixar nas aldeias os materiais: um para cada aldeia - em minha ingenuidade e, agora percebo, incoerência. Mas os Xikrin sempre acham um meio de fazer as coisas a seu modo e de fazê-las acontecer. De imediato, surgiram cartões de memória para que eu gravasse neles as "fotos de antigamente" e os áudios de festas. ${ }^{23}$ Em pouco tempo, tomaram conta de todo o processo - e o computador que continha o material logo estava em suas mãos, e eles gerenciavam então o que iria ser gravado e para quem. Mais revelador ainda, esse material, agora digital, se mostrou tão perecível quanto as fotos em papel. Afinal, como já disse logo de início, as crianças são suas prioridades, e elas sempre têm novos filmes e desenhos animados que querem assistir, e que serão então gravados nos mesmos cartões de memória em que estavam as fotos e os áudios "de antigamente". A cada dia recebo ao menos um pedido, por telefone, para mandar por Facebook ${ }^{24}$ ou por WhatsApp os mekaron tum. E, já está claro, esta será uma demanda infinita, em uma mobilidade digital que em tudo se assemelha a essas outras mobilidades desde sempre vividas, a territorial, a aldeã, a do aparentamento e inimização, e a do kukradjà. *

* Manuscrit reçu en février 2020, accepté pour publication en octobre 2020.

23. O fato de meus equipamentos à época não terem me permitido fazer filmes é sempre e continuamente lamentado, e esta é uma informação que eles parecem esquecer sempre, perguntando continuamente pelos filmes dos rituais "de antigamente".

24. Convencê-los de que eu não poderia postar em suas Time Lines as fotos foi todo um outro processo, já que isso, temia, pudesse configurar uso indevido de suas imagens. O modo que encontramos é que a equipe de alunos com os quais trabalho leva sempre um carregamento de cartões de memórias cheios de fotos, nominais, com as escolhidas por cada um. E eu não postar no Facebook, evidentemente, não os impede de fazê-lo - e frequentemente passa pela minha Timeline fotos que tirei e que são circuladas por eles. 
Agradecimentos - Estas atividades foram viabilizadas pelo financiamento do CNPq do Projeto Ver, ouvir, registrar: modos de aprender e contar o mundo entre os Xikrin do Bacajá (Processo 460380/2014-1, aprovado no Edital Apoio a Projetos de Pesquisa/ MCTI/CNPQ/Universal 14/2014), que permitiu a digitalização do material e a viagem por todas as aldeias da Terra Indígena Trincheira-Bacajá para sua apresentação, com uma equipe e os equipamentos necessários. Agradeço a Camila Boldrin Beltrame, à época minha orientanda de doutorado na UFSCar, por fazer parte de todo o projeto, em especial ao tratar da digitalização do material, compor a equipe que me acompanhou na viagem e registrá-la. Agradeço a Bep-tô Xikrin (Zé), Tekàkdjy Xikrin (Véinho) e Takàk-jakare Xikrin (Koka) por me auxiliarem na seleção das fotos a serem mostradas, ainda na cidade de Altamira/Pará, e muito especialmente a Takàk-jakare (Koka), por estar sempre ao meu lado explicando e traduzindo a proposta, assim como a Tum-re e Nhoka Xikrin, que viajaram também conosco apoiando as atividades. Não posso deixar de agradecer ao nosso piloto, conhecido como Jacaré, que cada vez mais se engajou na proposta e acompanhou as atividades. Agradeço ainda a minhas professoras Lux Vidal, Manuela Carneiro da Cunha e Beatriz Perrone-Moisés e a meus orientandos que trabalham e trabalharam comigo na região, e que muito ajudadam para a minha compreensão de tudo o que está aqui: Stéphanie Tselouiko, Thaís Mantovanelli, Jucimara Cavalcante, Rafaela Soldran, com os Xikrin; Xanda Miranda, com os Asurini do Kwatinemo; Eduardo Belezzini, com os Arara do Laranjal; e Ana Elisa Santiago, com os serviços voltados a indígenas em Altamira. Não posso deixar de agradecer aos Xikrin que, como se verá, me ensinaram, com grande vontade, tudo o que aprendi, e por me fazerem o mais mebengokré possível.

\section{Referências bibliográficas}

Álvares Myriam Martins

2018 Alteridade e história entre os Maxakali, Tese (doutorado), Centro Filosofia e Ciências Humanas, Programa de Pós-Graduação em Antropologia Social, Universidade Federal de Santa Catarina, Florianópolis.

Carneiro da Cunha Manuela

1978 Os mortos e os outros. Uma análise do sistema funerário e da noção de pessoa entre os Krahó, Hucitec, São Paulo.

2009 Cultura com Aspas e Outros Ensaios, Cosac Naify, São Paulo.

Carneiro da Cunha Manuela e Pedro de Niemeyer Cesarino (orgs.)

2016 Políticas culturais e povos indígenas, Editora UNESP, São Paulo.

Coelho de Souza Marcela e Edilene Cofacci de Lima

2010 Conhecimento e cultura. Práticas de transformação no mundo indígena, Athalaia Gráfica e Editora/CAPES, Brasília.

Beltrame Camila Boldrin

2013 Etnografia de uma escola xikrin, Dissertação (Mestrado) em Ciências Humanas, PPGAS, Universidade Federal de São Carlos, São Carlos. 
Retornando sua coleção de material audiovisual: os dilemas de uma antropóloga

CoHn Clarice

2000 A criança indígena. A concepção xikrin de infância e aprendizado, Dissertação (Mestrado), Departamento FLA, PPGAS, Faculdade de Filosofia, Letras e Ciências Humanas, Universidade de São Paulo, São Paulo.

2001a "Índios missionários: cultos protestantes entre os Xicrin do Bacajá", Revista Campos, 1 (1), p. 9-30.

2001b "Escolas indígenas do Maranhão: um estudo sobre a experiência dos professores indígenas", in Aracy Lopes da Silva e Mariana Kawall Leal Ferreira (orgs.), Práticas pedagógicas na Escola Indígena, EDUSP, São Paulo.

2005 Relações de Diferença no Brasil Central. Os Mebengokré e seus Outros, Tese (Doutorado), Departamento de Antropologia, Faculdade de Filosofia, Letras e Ciências Humanas, Universidade de São Paulo, São Paulo.

2006 "Discursos políticos e objetificação da cultura nos Mebengokré-Xikrin", comunicação apresentada ao "GT 14 - Os regimes de subjetivação ameríndios e a objetivação da cultura" no " $30^{\circ}$ Encontro Anual da ANPOCS” [ 24 a 28 de outubro de 2006], http://www.anpocs.com/index.php/encontros/papers/30-encontro-anualda-anpocs/gt-26/gt14-18/3352-ccohn-discursos/file, consultado em 13/11/2020.

2010 “A criança, a morte e os mortos: o caso Mebengokré-xikrin”, Horizontes Antropológicos, 16 (34), p. 93-115.

2014 "O fim do mundo como o conhecemos: os Xikrin do Bacajá e a barragem de Belo Monte", in João Pacheco de Oliveira e Clarice Cohn (orgs.), Belo Monte e a Questão Indígena, ABA, Brasília.

2016 "A cultura nas escolas indígenas", in Manuela Carneiro da Cunha e Pedro de Niemeyer Cesarino (orgs.), Políticas culturais e povos indígenas, Editora UNESP, São Paulo.

2019 "Caderno de fotos: a etnógrafa, a fotógrafa e a retratista",r@u. Revista de Antropologia da UFSCar, 11 (1), p. 458-472.

Demarchi André

2014 Kukràdjà Nhipêjx: fazendo cultura: beleza, ritual e politicas da visualidade entre os Mebêngôkre-Kayapó, Tese (Doutorado), apresentada ao Programa de pós-graduação em Sociologia e Antropologia (PPGSA), Universidade Federal do Rio de Janeiro, Rio de Janeiro.

EwArT Elizabeth

2012 "Making and unmaking Panará beadwork: or, how to overcome the fixity of material things", Anthropology and Humanism, 37 (2), p. 177-190.

FISHER William H.

1991 Dualism and its discontents: social process and village fissioning among the Xikrin-Kayapó of central Brazil, Tese (Doutorado), Antropologia, Cornell University, Cornell.

2000 Rain Forest Exchanges. Industry and Community on an Amazonian Frontier, Smithsonian Institution Press, Washington.

GianNini Isabelle Vidal

1991 A ave resgatada: “A impossibilidade da leveza do ser”, Dissertação (Mestrado), Antropologia, PPGAS, Faculdade de Filosofia, Letras e Ciências Humanas, Universidade de São Paulo, São Paulo. 
Gordon César

2001 "Nossas utopias não são as deles: os Mebengokre (Kayapó) e o mundo dos brancos", Sexta Feira, 6 ]Utopia[ (São Paulo, Editora 34/Pletora), p. 126-136.

2006 Economia Selvagem. Ritual e Mercadoria entre es índios Xikrin-Mebêngôkre, Editora UNESP, ISA, São Paulo/NuTI, Rio de Janeiro.

Gow Peter

1991 Of Mixed Blood. Kinship and History in Peruvian Amazonia, Clarendon Press, Oxford.

GRAHAM Laura R.

2018 Performance de Sonhos. Discursos de imortalidade Xavante, Universidade de São Paulo, São Paulo.

LEA Vanessa Rosemary

2006 "La muerte entre los Mebêngôkre del Brasil Central", in David R. Quispe, Herrera, Limberg (orgs.), Imagen de la muerte, Universidad Nacional Mayor de San Marcos/Editorial Línea Andina, Lima.

2007 "Uma aula de choro cerimonial Mẽbêngôkre", in Aryon Dall'Igna Rodriques e Ana Suelly Arruda Câmara Cabral (orgs.), Línguas e Culturas Macro-Jê, Editora da UnB/Finatec, Brasília.

2012 Riquezas intangíveis de pessoas partíveis, Edusp, São Paulo.

Mantovanelli Thaís

2016 Os Xikrin do Bacajá e a Usina Hidrelétrica de Belo Monte: uma crítica indígena à política dos brancos, Tese (Doutorado), Antropologia, PPGAS, Universidade Federal de São Carlos, São Carlos.

Oliveira João Pacheco de e Clarice Cohn (orgs.)

2014 Belo Monte e a Questão Indígena, ABA, Brasília.

SAntana José Valdir Jesus de e Clarice CoHN

2016 "Formas de estar na cultura na e pela escola: o caso dos indígenas Tupinambá de Olivença/BA", Revista Anthropológicas, 27 (1), p. 218-244.

2018 "A escola dos Tupinambá de Olivença-BA: alguns apontamentos", Espaço Ameríndio, 12 (1), p. 50-80.

TSELouiko Stéphanie

2018 Entre ciel et terre. Socio-spatialité des Mebengôkré-Xikrin. Terre Indigène Trincheira Bacajá (TITB, Pará, Brésil), Tese (doutorado), Antropologia Social e Etnologia, EHESS, Paris/Universidade Federal de São Carlos, São Carlos.

TURNER Terence

1991 "Baridjumoko em Altamira", in Povos indígenas no Brasil, 1987-1990, Cedi (Aconteceu Especial, 18), São Paulo.

1993 "Imagens desafiantes: a apropriação kayapó do vídeo", Revista de Antropologia, 36, p. 181-121.

VERSWIJVER Gustaaf

1992 The Club-Fighters of the Amazon. Warfare among the Kayapo Indians of Central Brazil, Rijkuniversiteit, Gent.

VIDAL Lux

1976 "As categorias de idade como sistema de classificação e controle demográfico de grupos entre os Xikrin do Cateté e de como são manipulados em diferentes 
Retornando sua coleção de material audiovisual: os dilemas de uma antropóloga

contextos", in Actes du XLII Congrès international des américanistes, Societé des Américanistes, Paris.

1977 Morte e Vida de uma Sociedade Indígena Brasileira, Hucitec, São Paulo.

1983 "A morte entre os índios Kayapó", in José de Souza Martins (org.), A morte e os mortos na sociedade brasileira, Hucitec, São Paulo.

1992 “A pintura corporal e a arte gráfica entre os Kayapó-Xikrin do Cateté”, in Lux Vidal (org.), Grafismo indígena, Studio Nobel/EDUSP, São Paulo, p. 143-189.

XIKRIN Ngrenh-Djam

2014 "O processo de construção de Belo Monte na fala de uma jovem Xikrin", in João Pacheco de Oliveira e Clarice Cohn (orgs.), Belo Monte e a Questão Indigena, ABA, Brasília. 
